Eli M. Brown MD, Vimala E. Kunjappan MD, Gaylord D. Alexander MD

\title{
Fentanyl/alfentanil for pelvic laparoscopy
}

Alfentanil, a new narcotic analgesic, was compared to fentanyt in a technique of balanced anaesthesia using thiopentone $5 \mathrm{mg} \cdot \mathrm{kg}^{-1}$ for induction of amaesthesia, and pancuronitm $60 \mu \mathrm{g} \mathrm{kg}^{-i}$ to facilitate intubation. The study group consisted of 80 female patients scheduled for peivic laparoscopy. The total dose of alfentanil averaged $2.06 \mathrm{mg}$ (range $1.5-2.5 \mathrm{mg}$ ) whereas the dose of fentanyl averaged $0.21 \mathrm{mg}$ (range $0.1-0.25 \mathrm{mg}$ ). There was no significant difference between the two groups in duration of anaesthesia, time to extubation, verbal response time or time to orientation to person, place and time. Following intubation, there was a significant rise in heart rate and blood pressure $(p<0.01)$ in boith groups, but. again, there was no difference between groups. Postoperatively, the respiratory rate was not below 12 per minute for any patient in the study and was comparable for the two groups. The only significant side effect was postoperative nausea which occurred in over 40 per cent of patients and was not significantly different befween the two groups.

We conclude that alfentanil is a suitable narcotic drug for short surgical pracedures on ambulatory patients, but the drug has no marked advantage over fentanyl for these procedures.

\section{Key words}

ANAESTHESIA: outpatient, ANAESTHETICS: alfentanil, fentanyl, intravenous, narcotics.

From the Department of Anesthesiology, Wayne State University School of Medicine, and the Department of Anesthesiology, Sinai Hospital of Detroit, Detroit, Michigan.

Address correspondence to: Eli M. Brown, M.D., Chairman, Department of Anesthesiology, Sinai Hospital of Detroit, 6767 West Outer Drive, Detroit, Michigan 48235.
Alfentanil is a very short-acting analgesic analog of fentanyl. Animal and clinical studies indicate that alfentanil has a duration of action one-third to one-half that of fentanyl, and an analgesic potency one-fifth to one-third that of fentanyl. ${ }^{1}$ These characteristics suggest that alfentanil should be a useful drug for anaesthesia in an ambulatory surgical sctting. The purpose of this study is to compare alfentanil with fentanyl as the narcotic analgesic used in a technique of balanced anaesthesia for pclvic laparoscopy in an ambulatory surgical setting.

\section{Methods}

The study group consisted of 80 female patients, 22 to 46 years old, ASA Physical Status Class I or II scheduled for pelvic laparoscopy under general anaesthesia (Table I). The study protocol was approved by the hospital Committee on Research for Human Studies. Informed consent was obtained from all patients

The patients were placed into one of two groups according to a standard random table so that 43 patients received alfentanil and 37 patients received fentanyl. The drugs were supplied in $5 \mathrm{ml}$ colourless ampoules which contained either alfentanil $500 \mu \mathrm{g} \cdot \mathrm{ml}^{-1}$ or fentanyl $50 \mu \mathrm{g} \cdot \mathrm{ml}^{-1}$. The study was carried out in a double-blind manner, and the code was not broken until the study was complete anc all conclusions drawn. A two-sided Student's t-test for comparison of population means with variance unknown and assumed unequal was used to analyze all data except for the data on nausea and vomiting. For these data, the test for comparison of two proportions was used. ${ }^{2}$ All patients were unpremedicated. Patients were monitored by blood pressure cuff, EKG and peripheral nerve stimulator. Patients were induced with thiopentone $5 \mathrm{mg} \cdot \mathrm{kg}^{-1}$ and pancuronium $60 \mu \mathrm{g} \cdot \mathrm{kg}^{-1}$ was administered to facilitate endotracheal intubation. Nitrous oxide 70 per cent and oxygen 30 per cent was administered 
TABLE I Study group

\begin{tabular}{lll}
\hline & $\begin{array}{l}\text { Aifentanil } \\
(N-43)\end{array}$ & $\begin{array}{l}\text { Fentanyl } \\
(N-37)\end{array}$ \\
\hline Age $\left(y r s .{ }^{*}\right)$ & $34.5(23-46)$ & $33.4(22-45)$ \\
Body wt. (kg)* & $60.0(45.5-109)$ & $60.5(47-89)$ \\
ASA status I & 39 & 35 \\
ASA status II & 4 & 2 \\
\hline
\end{tabular}

"Mean (ranges).

during the induction period. Following induction of anaesthesia, each patient received empirically $2 \mathrm{ml}$ of the unknown narcotic. If the heart rate rose more than 20 per cent above the preoperative value, additional narcotic was administered in one $\mathrm{ml}$ increments until the heart rate returned to within 20 per cent of the preoperative value.

When the peripheral nerve stimulator indicated that approximately 90 per cent twitch depression had been achieved, an endotracheal tube was inserted. If this procedure caused a rise in heart rate or blood pressure, additional narcotic was administered. The patient was placed on a volume limited ventilator at a tidal volume of $8 \mathrm{ml} \cdot \mathrm{kg}^{-1}$ and a rate of 10 breaths minute ${ }^{-1}$. During maintenance of anaesthesia, the need for additional narcolic was determined according to clinical signs such as tearing, pupillary dilatation, increase in heart rate or blood pressure. The peripheral nerve stimulator was used to determine the need for additional muscle relaxant. No untoward events occurred in any of the patients during surgery.

Following completion of the surgical procedure, each patient received neostigmine $2.5-5 \mathrm{mg}$ mixed with glycopyrrolate $0.5-1.0 \mathrm{mg}$. The nitrous oxide was discontinued and the patient received 100 per cent oxygen until it was determined that the patient could be safely extubated. The time lapse from extubation to appropriate response to verbal commands and to correct orientation to person, place and time was tabulated. No patient was removed from the operating table until she could maintain head lift for five seconds. Naloxone was not administered to any patient in this study. The patients were observed in the postanaesthesia care unit for not less than three hours. The nurses in the postanaesthesia care unit were asked to record blood pressure, heart rate, and respiratory rate every five minutes. They also recorded the presence of any untoward side effects. Patients were dis- charged when they met the usual criteria including absence of signs of orthostatic hypotension on standing. Patients were called at home on the day following surgery to detect the presence of any late untoward effects and to determine the patient's evaluation of the anaesthetic experience including the possibility of awareness during anaesthesia.

\section{Results}

The duration of anaesthesia among the two groups of patients was not significantly different, nor was the reaction time on emergence (Table II). The total dose of alfentanil used varied between 1.5 and $2.5 \mathrm{mg}$ averaging $2.06 \mathrm{mg}$, whereas the dose of fentanyl varied between 0.1 and $0.25 \mathrm{mg}$, averaging $0.21 \mathrm{mg}$. When contacted on the day following surgery, none of the patients indicated awareness during the surgical procedure. The systolic blood pressure decreased slightly following induction of anaesthesia and prior to intubation while the heart rate rose slightly. There was no significant difference in these parameters among patients who received either narcotic (Table III). Following intubation, there was a significant rise in heart rate and systolic blood pressure $(p<0.01)$ in both groups, but, again, therc was no sigrificant difference between the groups. Postoperatively, the respiratory rate was not below 12 breaths $\mathrm{min}^{-1}$ for any patient in the study and was comparable for the two groups (Table IV). The only significant untoward side effect that occurred in these patients was postoperative nausea. Nausea occurred in over 40 per cent of patients in each group, but in most instances, it was characterized as mild. The incidence of nausea and vomiting was not significantly different between the two groups of pratients (Table V).

\section{Discussion}

This study was designed to determine whether or not alfentanil was superior to fentanyl in the

TABLE 11 Time to reaction on emergence* (minutes)

\begin{tabular}{lccl}
\hline Parameter & Alfentanil & Fentanyl & Difference \\
\hline Duration of anaesthesia & $31.5 \pm 8.0$ & $35.1 \pm 13.4$ & NS \\
Time to extubation & $3.3 \pm 2.4$ & $3.3 \pm 2.2$ & NS \\
Vcrbal rcsponse time & $3.6 \pm 2.3$ & $4.0 \pm 2.0$ & NS \\
Time to orientation & $4.9 \pm 2.7$ & $5.6 \pm 3.9$ & NS \\
\hline
\end{tabular}

*All values are mear \pm S.D. 
TABLE III Cardiovasculur changes*

\begin{tabular}{lccl}
\hline & Alfentamil $(N-43)$ & Fentanyl $(N-37)$ & Difference \\
\hline $\begin{array}{l}\text { Systolic blood pressure (lorr) } \\
\text { Preinduction }\end{array}$ & $116.5 \pm 16.4$ & $117.0 \pm 15.1$ & N.5 \\
Postinduction & $11.7 \pm 19.8$ & $114.3 \pm 15.8$ & NS \\
Preintubation & $109.2 \pm 16.4$ & $112.2 \pm 16.3$ & NS \\
Postintubation & $125.1 \pm 21.6 \dagger$ & $134.3 \pm 22.5 \dagger$ & NS \\
& & & \\
Heart rale (B.P.M.) & & & \\
Preinduction & $84.7 \pm 13.8$ & $84.8 \pm 13.6$ & NS \\
Postinduction & $87.9 \pm 15.0$ & $85.8 \pm 12.0$ & NS \\
Prcintubation & $85.3 \pm 10.4$ & $87.1 \pm 11.1$ & NS \\
Postintubation & $104.4 \pm 14.2+$ & $104.8 \pm 12.7 \dagger$ & NS \\
\hline
\end{tabular}

*Mean $\pm \mathrm{SD}$.

$\dagger=$ peak value following intubation. This value is significantly differen frorr values obtained one minute prior to intubation.

technique of balanced anaesthesia that we routinely employ for pelvic laparoscopy in our ambulatory surgery setting. During induction, the dose of narcotic administered was that amount necessary to maintain heart tate within 20 per cent of the preoperative value. During maintenance, additional narcotic was administered in responsc to clinical signs of light anaesthesia as determined by one of three experienced anaesthesiologists. Using these criteria for narcotic administration, we found that the total dose of narcotics administered was not equipotent. Instead, the dose ratio of alfentanil to fentanyl was $10: 1$ rather than the $5: 1$ ratio determined in animals. The fact that a relatively larger dose of alfentanil was necessary in our study may have resulted from: (1) a difference between relative potency of the drugs in animals and man; (2) a shorter duration of effect of alfentanil; (3) a variation in the response of patients to narcotic drugs; or a combination of all three.

Although the dose of narcotic (along with the thiopental and nitrous oxide) was sufficient to produce unconsciousness in all patients, the dose was. not sufficient to completely block the autonomic response to intubation. A transient rise in heart rate and blood pressure following intubation is not unusual with most techniques of general anaesthesia except when high dose narcotic techniques are used for induction of anaesthesia. The rise in blood pressure and heart rate in our patients was controlled by the administration of additional narcotic following intubation.

The awakening time as determined by the time to extubation, verbal response, and orientation was not significantly different between the two groups of patients. The failure to detect a difference in awakening time is not surprising because of the relatively small total dose of narcotic used. At these doses, redistribution mechanisms account for the termination of narcotic effect. Since the major pharmacokinetic difference between fentanyl and alfentanil is in the terminal elimination phase, one would expect to see a difference in awakening time only when larger total doses of the drugs are used. Respiratory depression was not a problem with either fentanyl or alfentanil. All patients had a respiratory rate greater than 12 breaths $\cdot \mathrm{min}^{-1}$ at the completion of the anaesthetic. Consequently, the use of naloxone was not necessary in any of the 80 patients included in the study.

The incidence of nausea was quite high in both groups. In most instances, however, the nausea was not distressing to the patients. There are a number of factors (age, emotional state, type and duration of surgical procedure) other than the narcotic that could contribute to nausea and vomiting. ${ }^{3-5}$ In addition, the large quantity of carbon dioxide

TABLE IV Respiratory rate* (breaths/minute)

\begin{tabular}{llll}
\hline & $\begin{array}{l}\text { Alfenlanil } \\
(N-43)\end{array}$ & $\begin{array}{l}\text { Fentanyi } \\
(N-37)\end{array}$ & Difference \\
Respiratory rate & $(17.98 \pm 2.47$ & $18.27 \pm 3.50$ & NS \\
\hline Entry to P.A.R. & $170 \pm 1.51$ & $20.60 \pm 1.90$ & NS \\
Highest & $20.10 \pm 1.90$ & $16.50 \pm 2.70$ & NS \\
Lowest & $16.50 \pm 1.90$
\end{tabular}

*Mean $\pm \mathrm{SD}$. 
TABLE V Untoward effects

\begin{tabular}{lcrl}
\hline & $\begin{array}{l}\text { Alfentanil } \\
(N-43)\end{array}$ & \multicolumn{1}{l}{$\begin{array}{l}\text { Fentanyl } \\
(N-37)\end{array}$} & Difference \\
\hline Nausea & $21(48.8 \%)$ & $15(40.5 \%)$ & NS \\
Distressing & $2(4.6 \%)$ & $5(13.5 \%)$ & NS \\
Non-distuessing & $19(44.2 \%)$ & $10(27.0 \%)$ & NS \\
Vomiting & $7(16.3 \%)$ & $8(21.6 \%)$ & NS \\
\hline
\end{tabular}

introduced into the peritoneal cavity during pelvic laparoscopy may have contributed to the high incidence of nausea.

We could detect no difference in patient acceptance of the technique. The only patients who complained were the few who vomited or experienced severe bouts of nausea.

We conclude that alfentanil is a suitable narcotic for short surgical procedures such as pelvic laparoscopy on ambulatory patients. However, because of the relatively small doses of narcotic required for these surgical procedures, alfentanil does not seem to have any advantage over fentanyl. Although alfentanil has a shorter duration of action, the total dose of each drug necessary to provide adequate anaesthesia, as judged by three experienced anaesthesiologists, resulted in no significant difference in either awakening time or the incidence of untoward side effects.

\section{References}

1 Bovill JG, Sebel PS, Blackburn CL, Heykants $J$. The pharmacokinetics of alfentanil - A new opioid analgesic. Anesthesiology 1982; 57: 439-443.

2 Johnson JL, Leone FL. Statisties and experimental design, p 234, Publisher, John Wiley \& Sons.

3 Bodman RI, Morton HJV. Thomas ET. Vomiting by outpatients after nitrous oxide anaesthesia. $\mathrm{B}_{\mathrm{T}}$ Med J 1960; 1: 1327-30.

4 Steward DJ. Experiences with an outpatient anesthesia service for children. Anesth Analg 1973; 52: 877-80.

5 Fahy $A$, Marshall $M$. Postanaesthetic morbidity in outpatients. Br J Anaesth 1969; 41: 433-8.

\section{Résumé}

Au cours d"anesthésie balancée employant du thiopental $5 \mathrm{mg} \cdot \mathrm{kg}^{-1}$ pour l'induction de l'anesthesie et du pancuronium $60 \mu \mathrm{g}^{\mathrm{kg}} \mathrm{g}^{-1}$ pour effectuer l'inubation, nous avons comparé $l$ alfentanil, un nouvel and'gésique morphinique au fentanyl. L'étude a été effectuée sur 80 sujets de sexe féminin subissant une laparoscopie pelvienne. La dose moyenne totale d" alfentanil était de $3.06 \mathrm{mg}(1.5$ à $2.5 \mathrm{mg}$ ) alors que la dose de fentanyl était de $0.21 \mathrm{mg}(0.1$ ḋ $0.25 \mathrm{mg}$ ). On n'a observé aucune différence significative entre les deux groupes en termes de durée d'anesthésie, de temps écoulé jusqu'à l'extubation, jusqu'd la réponse aux ordres verbaux, jusqu' à l'orientation dans le temps et l'espace. A la suite de l' extubation, on a observé une augmentation significative de la fréquénce cardiaque et de la pression anérielle $(p<0.01)$ dans les deux groupes mais ici encore on n'a pas abservé de différence entre les groupes. En période post-opératoire, la fréquence respiratoire $n^{\prime}$ a jamais été en bas de 12 a la minute, fréquence qui est demeurée comparable dans les deux groupes. Le seul effet secondaire indésirable observé a été la nausée post-opératoire qu'on a détectêe chez plus de 40 pour cent des malades darts "un et l'autre groupe.

Nous en concluons que l' alfentanil est un morphinique qui se prête à l' anesthésie pour opération de courle clurèe chez des malades ambulatoires mais ce nouveau médicamemi ne nous paraît pas présenter d'avartages marqués sur le fentanyl. 